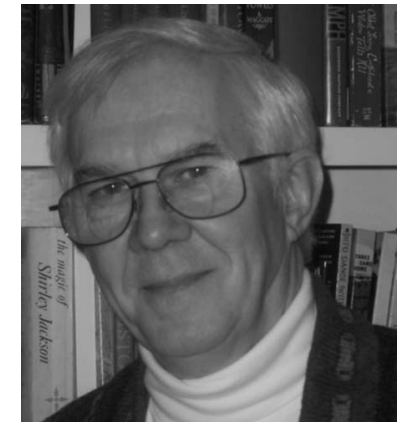

\title{
Those Ditsy Scientists!
}

It has gotten more difficult for news anchors these days. They can no longer report stories that end with a knowing nod at the antics of some ditsy blonde or brunette. If the story is told by a late-night comedy host, such as Jay Leno or David Letterman, it would not create any difficulties, but these politically correct days it's harder to get a newscast-ending giggle...unless it concerns scientists.

On any given weeknight you may hear a story on the nightly news that goes something like this:

"Scientists studying Gleeber's syndrome have found that the use of kazofrazanol, also known by its trade name, Elexara, does not prevent the symptoms of the disease as claimed by its makers, PharmMach. Instead, the latest research has found that the drug masks the symptoms by causing uncontrollable fits of giggling. Earlier work by a group from the University of Northwest South Dakota at Minneapolis has been shown to be faulty because the sample in the initial study was too small and included too many Minnesotans. Because the incidence of Gleeber's is 1 in 3 million, the earlier study was only able to find 4 people who may suffer from the disease. The new study has shown that Gleeber's syndrome can be cured with the administration of a jelly donut when the symptoms appear.

"Well, it looks like those silly scientists have gotten it wrong again. Perhaps we should award the authors of this new study a jelly donut for their work. But I'd hold off because you can't be sure those scientist have finally gotten it right. That's all the news for tonight! Stay tuned for Jeopardy."

And what are viewers to think of such a report? Although it gets the chuckles that such a piece was de-

signed to elicit, this type of comment on scientific reverses transmits to the public that scientific results are unreliable and will be replaced by the opposite conclusion later on.

Although news anchors introduce most reports in science, the networks have reporters assigned to that specific beat. Most of these journalists have sufficient training to know that science is a perfectible process and that there are differences among the basic sciences such as physics and chemistry, the analytical sciences such biology and geology, and the medical sciences. But when no distinction is made between an advance in physics and the latest drug study, people are given a skewed understanding of the scientific process - a process that has benefited them greatly. There is a disconnect between the hard news that is reported and the context (introduction and summary) in which it is presented.

Granted, the news media does a poor job of making important distinctions when reporting advancements in medical science and in describing the significance and certainty of results. Almost all but the most spectacular results in the physical sciences are ignored, while research in the life sciences is treated as a consumer interest story. It would be honest and prudent for media reporters to qualify the reliability of such reports, but the only qualification for most stories is that the treatment/procedure/ drug will not be available for 2/3/4 years.

Other qualifications that are rarely given are items like who paid for the study, what differences there were between competing studies, and whether affected groups are at greater risk than the population as a whole. By this time you would think that journalism, with accuracy as its controlling factor, would try in the time and space available for a story to make these distinctions and for an anchor to stifle the writers who want to supply silly punch lines at the expense of denigrating the scientific pursuit of knowledge.

Perhaps it is asking too much of an institution that used to be ruled by journalists like Edward R. Murrow. News has become part of the entertainment business and it may be asking too much to urge a considered treatment of important science. It may be that it is up to us scientists and engineers to remind others when contradictory science results are discussed that science is a process. It proceeds from what we know to what we can verify. Only by permitting the correction of earlier work do we progress.

\section{Donald C. O'Shea
Editor \\ Donald C. O'Shea
Editor}

